\title{
Experimental Analysis of an Electric Minibus with Small Battery and Fast Charge Policy
}

\author{
R. Di Rienzo*, F. Baronti*, F. Vellucci ${ }^{\S}$, F. Cignini**, F. Ortenzi ${ }^{\S}$, G. Pede ${ }^{\S}$, R. Roncella*, and R. Saletti* \\ ${ }^{*}$ Dip. di Ingegneria dell'Informazione, Università di Pisa, Italy \\ $\S$ Laboratorio Veicoli a Basso Impatto Ambientale, ENEA, Santa Maria di Galeria (Roma), Italy \\ ** Università La Sapienza, Centro di ricerca per il trasporto e la logistica, Roma, Italy
}

\begin{abstract}
The lead-acid battery of an electric minibus has been replaced with a smaller size lithium-ion battery system consisting of standard $12 \mathrm{~V}$ modules and a hierarchical battery management system. The minibus has experimentally been tested to show that the reduced battery capacity, which also cuts costs, does not affect the daily operational mission. This is assuming that the driving phases are alternated with fast charging periods. Experiments show that fast charging of 8 min guarantees up to $1 \mathrm{~h}$ of operation.
\end{abstract}

\section{INTRODUCTION}

The Kyoto protocol requires that the greenhouse gas (GHG) emissions within the European Union in 2050 are about 80 $95 \%$ below the 1990 levels. The protocol suggests halving the number of conventional vehicles by 2030 and their complete elimination by 2050 . Since a reduction of mobility is not a viable option, a realistic solution can be the increase of public transportation based on the sustainable energy paradigm [1], [2].

A study by the Joint Research Center (JCR) in Ispra (Italy) [3] shows that the average length covered by a vehicle in a single trip is about $5-20 \mathrm{~km}$. The study is based on the GPS data collected from 16000 vehicles in the Italian province of Modena in May 2011. According to these driving range data, electrified vehicles equipped with the currently available battery technology are a feasible solution and a very good opportunity to meet the protocol requirements. A large GHG emission reduction may also be achieved by the electrification of public transportation, especially in small cities and historical city centres. This concept has successfully been applied in Coimbra (Portugal), where a fleet of electric minibusses for tourists has been introduced in 2003 [4].

Commercial electric minibusses are usually equipped with lead-acid batteries. This mature battery technology has the disadvantage of a low gravimetric energy density and short lifetime, especially when subjected to deep discharges and high currents [5], as it happens in this application. However, the replacement of the traction battery with one of higher performance significantly increases the minibus costs. This issue is addressed in [6], where the authors conducted a simulative study to demonstrate the effectiveness of replacing the original lead-acid battery of a minibus with a lithium one. The lithium battery technology provides indeed higher energy and power densities, together with a longer lifetime [7].
TABLE I

CHARACTERISTICS OF THE CASE-STUDY ELECTRIC MINIBUS

\begin{tabular}{lc}
\hline $\begin{array}{l}\text { Curb weight } \\
\text { (without the traction battery) }\end{array}$ & $(2800 \pm 100) \mathrm{kg}$ \\
$\begin{array}{l}\text { Length } \\
\text { \# Passengers }\end{array}$ & $5.1 \mathrm{~m}$ \\
Traction power & 27 (10 of which are seated) \\
$\begin{array}{l}\text { Average energy } \\
\text { consumption per kilometer }\end{array}$ & $25 \mathrm{~kW}$ (peak), $20 \mathrm{~kW}$ (nominal) \\
\hline $\begin{array}{l}\text { Original lead acid battery } \\
\text { Volume available for the battery }\end{array}$ & $500 \mathrm{~W} \mathrm{~h} \mathrm{~km}^{-1}$ \\
\hline
\end{tabular}

This work aims at describing the implementation and test of an electric minibus based on a lithium battery and the fast charging concept. This allows the reduction of the battery capacity by alternating the driving phases with rapid charging periods. A preliminary study of the battery design has been carried out in [8], which suggested that a modular architecture based on $12 \mathrm{~V}$ standard modules may be effective in reducing costs due to the economies of scale. A first implementation of the standard module has been described in [9], [10]. The application of the fast charging concept to local public transportation is discussed in [11]. The current work provides an insight into the actual battery implementation and its integration into an electric minibus, similarly to what done in [6]. Moreover, this work reports on the experimental campaign carried out on a dynamometer chassis and discusses the experimental results in the framework of the fast charging scenario outlined in [12].

The paper is organized as follows. The target electric minibus and the battery charger representing the case-study are described in Section II. Section III provides details of the battery implementation. The experimental test-bed and results are explained in Section IV. Finally, Section V draws some conclusions.

\section{CASE-STUDY}

This Section presents the electric minibus and the battery charger, which constitute the starting points of this work.

\section{A. Electric minibus}

The electric minibus used in this work is the TECNOBUS Gulliver U520, shown in Fig. 1. It was originally equipped 


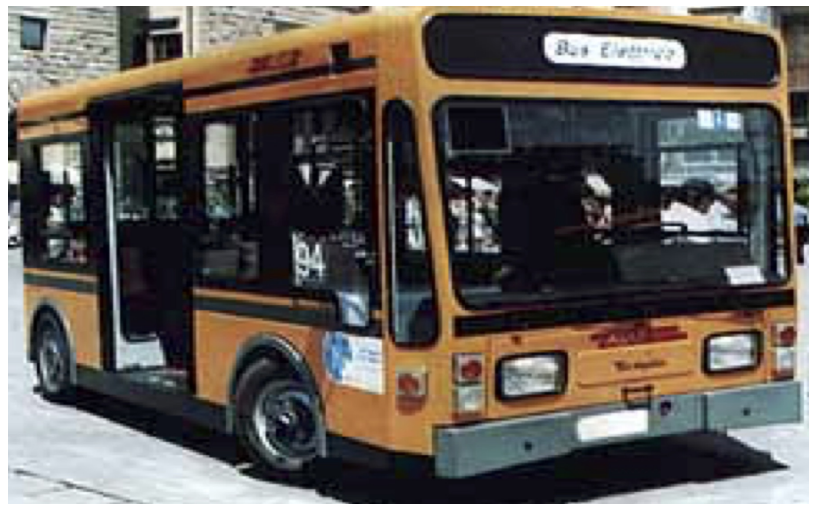

Fig. 1. Photograph of the electric minibus used in this work.

TABLE II

CHARACTERISTICS OF THE BATTERY CHARGER

\begin{tabular}{lc} 
Input & $400 \mathrm{~V}$ three-phase $\mathrm{AC}, 50-60 \mathrm{~Hz}$ \\
Output voltage & $60 \mathrm{~V}$ to $87.6 \mathrm{~V}$ \\
Continuous output current & $360 \mathrm{~A}$ \\
Continuous power @ $72.8 \mathrm{~V}$ & $26 \mathrm{~kW}$ \\
Efficiency & $>85 \%$ \\
\hline
\end{tabular}

with a $72 \mathrm{~V} 585 \mathrm{Ah}$ lead-acid battery. The minibus is provided with a $25 \mathrm{~kW}$ electric motor with a maximum torque of $235 \mathrm{Nm}$ at $950 \mathrm{rpm}$. The energy consumption is about $500 \mathrm{~W} \mathrm{~h} \mathrm{~km}^{-1}$ and the speed is limited at $33 \mathrm{~km} \mathrm{~h}^{-1}$ by the vehicle control unit. The main characteristics are summarized in Table I.

\section{B. Battery charger}

The battery charger was selected from commercially available devices, in order to reduce the initial cost of the project. The charger is manufactured by Zivan. It consists of four RG9 modules connected in parallel capable of providing an overall continuous charging power of $26 \mathrm{~kW}$. It can be controlled via a Controller Area Network (CAN) bus interface. Its main characteristics are summarized in Table II.

\section{BATTERY IMPLEMENTATION}

The lithium battery has been designed to be electrically compatible with the original lead-acid one. The minibus electric propulsion system can thus be reused. Therefore, the nominal voltage of the new battery must be $72 \mathrm{~V}$, a value achieved by 6 standard $12 \mathrm{~V}$ battery modules [9], [10] connected in series. The battery capacity has been chosen to be $240 \mathrm{~A}$ h. This choice provides a good trade-off between the battery cost and the driving range (approximately $30 \mathrm{~km}$, given a $500 \mathrm{~W} \mathrm{~h} \mathrm{~km}^{-1}$ energy consumption). Such a relatively small sizing of the battery energy is possible thanks to the fast charging concept, which allows the energy consumed for the journey to be balanced with the energy recharged at the bus stops [12].

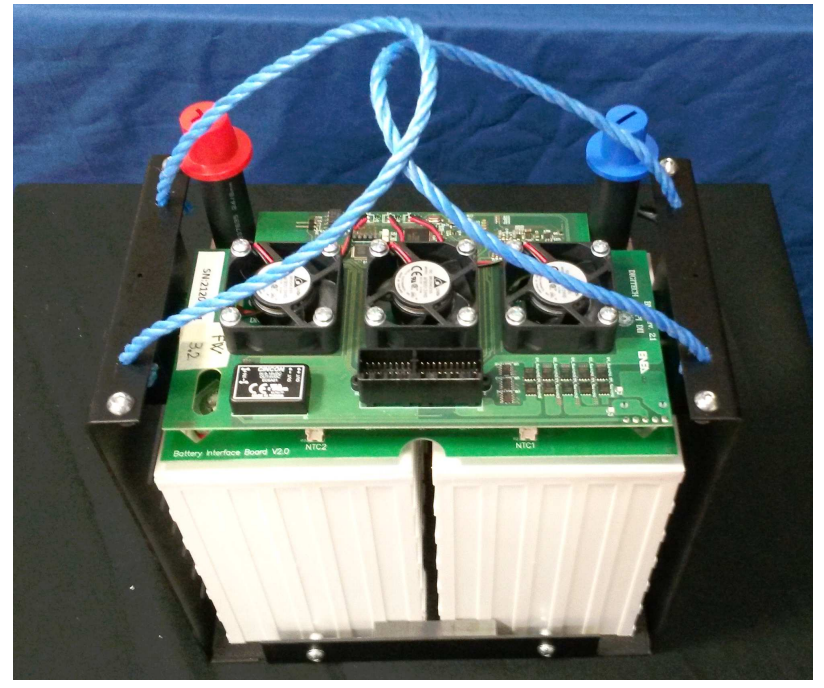

Fig. 2. Photograph of the standard $12 \mathrm{~V} 60 \mathrm{~A} \mathrm{~h}$ battery module (the case lid has been removed to show the module management (MMU) electronic boards.

TABLE III

CHARACTERISTICS OF THE LFP CELLS (HP-PW-60AH)

\begin{tabular}{lc}
\hline Nominal voltage & $3.2 \mathrm{~V}$ \\
Nominal capacity & $60 \mathrm{~A} \mathrm{~h}$ \\
Dimensions (L x W x H) & $(114 \times 61 \times 203) \mathrm{mm}^{3}$ \\
Weight & $2.04 \mathrm{~kg}$ \\
Working temperature (discharge) & -20 to $65^{\circ} \mathrm{C}$ \\
Working temperature (charge) & 0 to $45^{\circ} \mathrm{C}$ \\
\hline
\end{tabular}

\section{A. Standard $12 \mathrm{~V}$ battery module}

A photograph of the designed standard $12 \mathrm{~V}$ battery module is shown in Fig. 2. The module incorporates 4 lithiumiron-phosphate (LFP) cells, whose main characteristics are summarized in Table III and an advanced module management unit (MMU). The core of the MMU is a 32-bit ARM CortexM3 microcontroller (LPC1754 from NXP). It manages the acquisition of the voltage and temperature of the 4 cells (via a dedicated stack monitor IC, the LTC6803-3 from Linear Technology), the activation of the module fans (which are controlled so that the maximum cell temperature is kept between two configurable thresholds) and the communication via an isolated CAN bus.

The MMU also includes a section for handling analog inputs and isolated general purpose (GP) I/Os. Two analog input channels can be connected to the LEM S/18 sensor, used to acquire the module current. The LEM S/18 is a bidirectional Hall Effect sensor with two output channels having different sensing ranges, namely, $\pm 30 \mathrm{~A}$ and $\pm 350 \mathrm{~A}$. The module current is numerically integrated by the microcontroller as part of the State-of-Charge (SoC) estimation algorithm [9], which is based on the Coulomb Counting method combined with Open Circuit Voltage (OCV) compensation [13].

An innovative feature of the MMU is the circuit for the active charge equalization of the battery cells. It is based on an isolated DC/DC converter (Cincon EC6A01) and a 


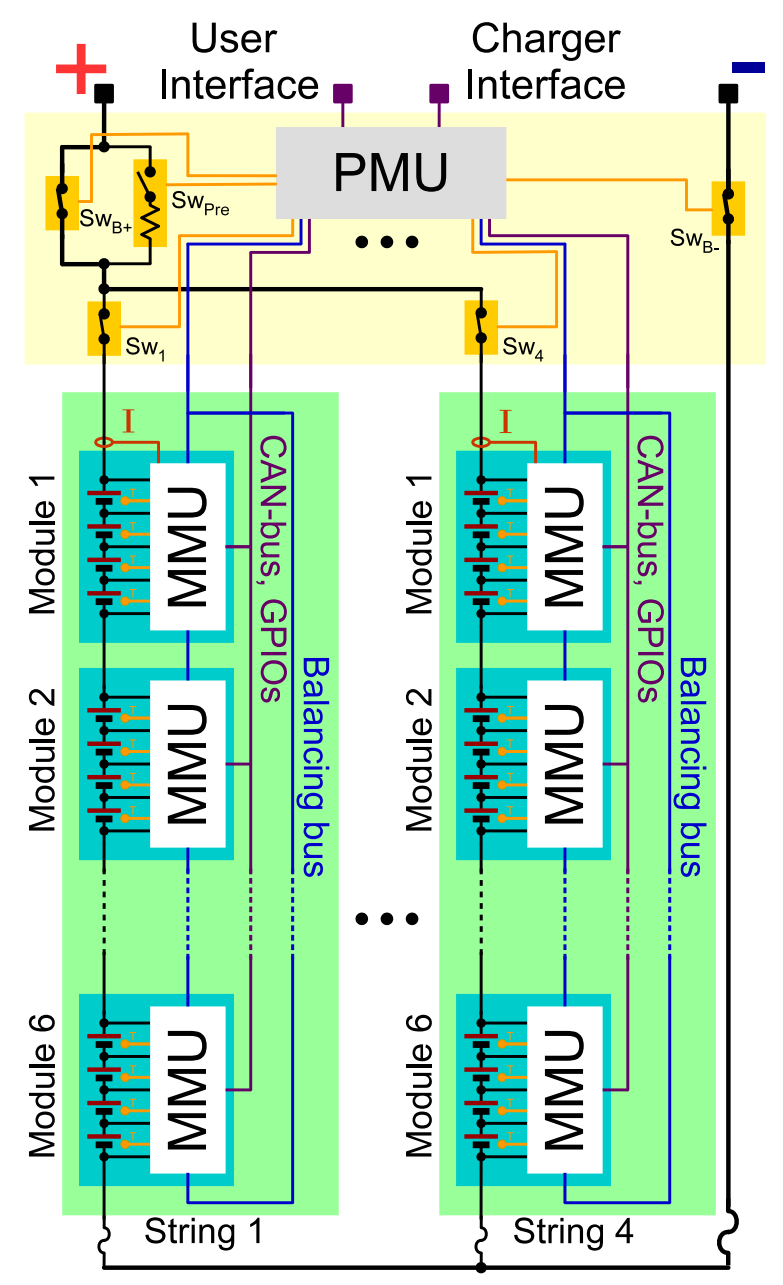

Fig. 3. Battery architecture.

switch matrix, which allows the individual connection of each module cell to the converter output (the converter is fed by the module voltage), thus implementing a module to cell active balancing topology. A novel and interesting feature of the circuit is the possibility of connecting the converter output also to a cell in another module, therefore enabling inter-module active balancing. This is obtained by a circular balancing bus, controlled in such a way that the battery is never short circuited, independently of any decision taken by the single microcontrollers in the MMUs [14].

Compared to a previous implementation of the battery module [9], [10], particular care has been given to the mechanical assembly and the thermal management to ensure good reliability. In particular, as seen in Fig. 2, the MMU consists of two boards: the upper one hosts the control circuitry, whereas the lower one acts as connection board holding the busbars and routing the cells' terminals and temperature sensors to the upper board. This dramatically reduces the complexity of the wire harness in the module increasing its reliability.

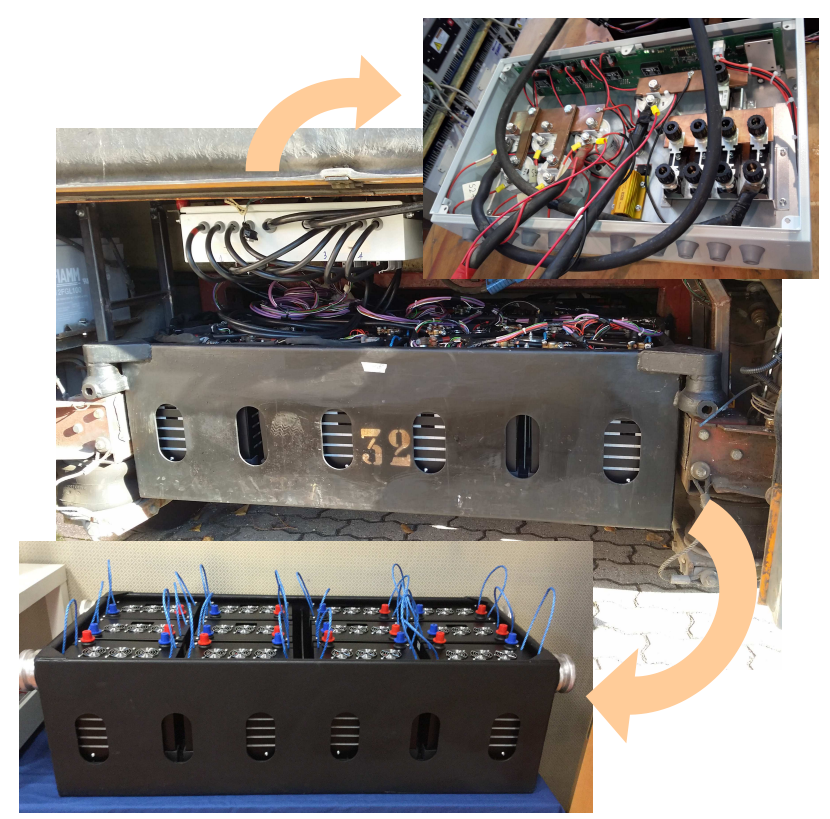

Fig. 4. Photograph of battery pack and its integration into the minibus. The lower inset shows one battery housing containing 2 battery strings, without the power and signal wire harness. The upper inset shows the pack management unit.

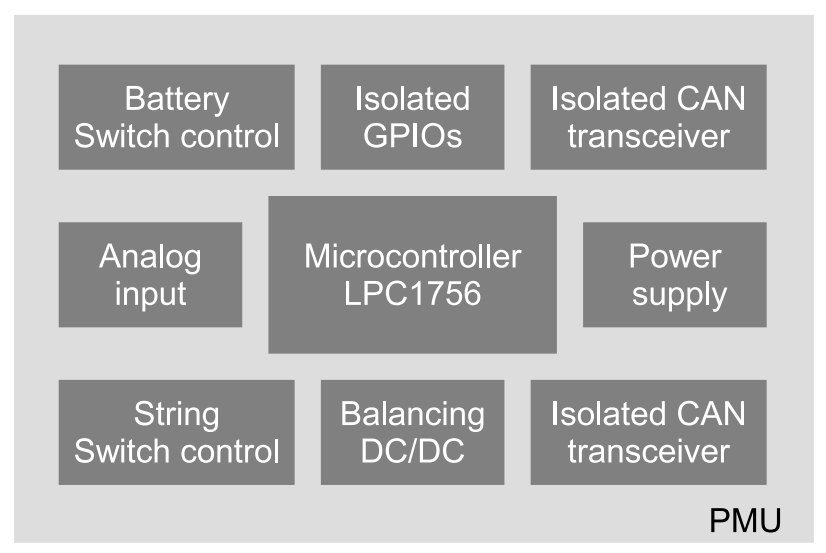

Fig. 5. Schematic block diagram of the PMU.

\section{B. Battery pack}

The battery pack consists of 24 standard modules to reach the required $72 \mathrm{~V}$ terminal voltage and the $240 \mathrm{~A} \mathrm{~h}$ battery capacity. The 24 modules are partitioned in 4 strings, each of them composed of 6 series-connected modules (see Fig. 3). Compared to other configurations that yield the same voltage and capacity, this topology simplifies the power connection between the modules' terminals, at the expense of a higher sensitivity to cell inhomogeneities, which reduce the usable capacity of the battery [15]. Moreover, the chosen topology facilitates the assembling of the battery pack and its integration into the minibus, as two complete strings can be allocated in each of two housings containing the original lead acid battery (see Fig. 4).

Fig. 3 shows the connections between the modules and the 
pack management unit (PMU). Each string has a local routing, which establishes the series connection of the 6 modules and the communication among the MMUs, and a global routing toward the PMU and its ancillary components. Consequently, there is no direct wiring between the two strings, which supports the above mentioned objective of simplifying the integration of the battery into the minibus. In order to reduce costs, only one current sensor connected to the Module 1 is used per string, as seen in Fig. 3. The same current flows indeed in all the modules of a string and its values is shared by the Module 1 to the other modules via the CAN-bus.

The battery connection to the load/charger is controlled by the switches $\left(\mathrm{Sw}_{\mathrm{B}+}, \mathrm{Sw}_{\mathrm{B}-}\right)$, in series with the positive battery terminal and the negative one, respectively. The switches are implemented with a power relay or contactor (Tyco EV200), which can carry a continuos current of $500 \mathrm{~A} @ 85^{\circ} \mathrm{C}$ and withstand a voltage of $320 \mathrm{~V}$. The same contactors are also used for the string switches $\left(\mathrm{Sw}_{1}-\mathrm{Sw}_{4}\right)$ that control the parallelization of the 4 strings, to reduce the bill of material. A pre-charge resistor and a relay are connected in parallel to the $\mathrm{Sw}_{\mathrm{B}+}$ switch. This limits the in-rush current flowing when the battery is connected to the load due to its input capacitance.

All the switches are driven by the PMU, which controls their state according to the commands received from the user interface (UI), the string total voltages, and the internal status of the modules. In particular, a string switch may be turned on only if the difference between the string voltage and the battery voltage is in the range of $\pm 3 \mathrm{~V}$ and if all the string modules are in the safe state. This avoids an extremely high circulating current between the strings because of their very low series resistance and keeps the voltage and the temperature of all the 4 module cells in their safe operating area. In more detail, the activation signal of a string switch, generated by the microcontroller inside the PMU, is AND-wired with the consent signals produced by 6 MMUs (and routed to the PMU through the isolated GPIOs). In this way, each module can interrupt the current flowing in the corresponding string independently of the PMU to achieve a prompt and robust protection mechanism.

As seen in the schematic block diagram of Fig. 5, the PMU is based on the NXP LPC1756 microcontroller, which belongs to the same family of the one used in the MMU, but with an additional CAN-bus peripheral. One CAN-bus peripheral is used for the communication with the modules and the other one for the communication with the battery charger. The PMU also incorporates 4 isolated DC/DC converters (one per string) powered by the string with highest voltage. The output of each converter is connected to the balancing bus of one of the 4 strings. Consequently, energy can be moved from the cells of the averagely more charged string to a generic cell of the battery. The MMU equalization method is used to balance the 4 cells in the module and this can be achieved in parallel for all the modules. After this step, cells are balanced within modules, but charge imbalance can still be present between cells belonged to different modules. The latter imbalance is recovered by using the PMU equalization method.

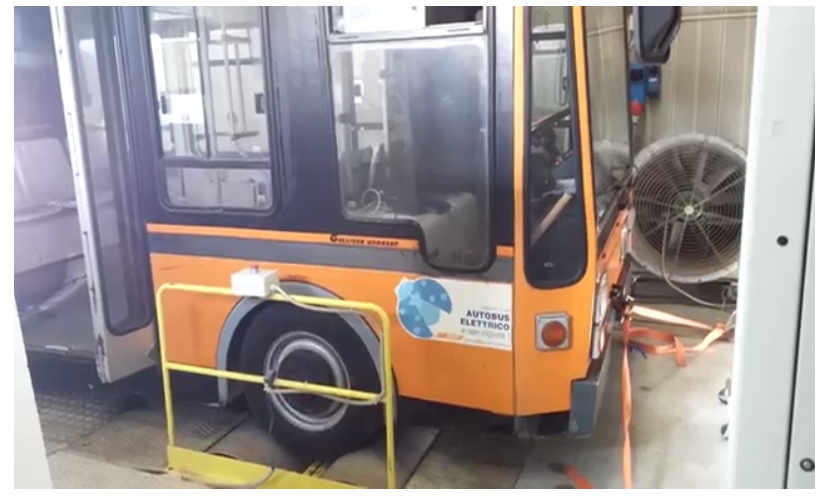

Fig. 6. Photograph of the minibus during a test session on the dynamometer chassis.

\section{EXPERIMENTAL VALIDATION}

\section{A. Experimental test-bed}

The battery pack has been assembled and mounted in the minibus, as shown in Fig. 4. An extensive test campaign has been carried out using a dynamometer chassis (see Fig. 6), which measures and stores mechanical quantities, such as speed and torque. The minibus performance in terms of energy consumption and driving range has been assessed using the Standardized On-Road Test (SORT) driving cycles, as defined by the international organisation for public transport authorities and operators (UITP).

During the tests the PMU is connected to a laptop which implements the UI developed in LabVIEW. Fig. 7 shows a screenshot of the UI, which allows the user to control, monitor and log the status of the battery. In particular, voltage, current, and temperature of each cell of the battery can be logged and saved for offline processing. Moreover, the UI makes it possible to individually turn on the 4 strings in the battery. This feature has been used to test the minibus when powered by 4 strings in parallel (full battery) and by just 2 strings (half battery). Fig. 8 displays the speed acquired by the dynamometer chassis and the electrical power provided by the battery, during two SORT 1 cycles.

\section{B. Experimental results}

1) Full battery case: Table IV summarizes the results of a test consisting of 86 repetitions of the SORT 1 cycle (corresponding to $31.7 \mathrm{~km}$ ), executed with the full battery, starting from the full charged state. The test was completed with success without fully discharging the battery. This means that the full battery can guarantee the expected driving range (see Section III). It is worth noting that the charge and energy provided by the battery is not uniformly distributed among the 4 strings. This is an undesired behavior, which tends to degrade the usable capacity of the battery. This is caused by variations in the characteristics of the strings connected in parallel, as discussed in [15]. In this case, we observed a significant variations in the string series resistance, especially between the first and fourth string. This phenomenon can mainly be ascribed to some critical aspects in the power connections 


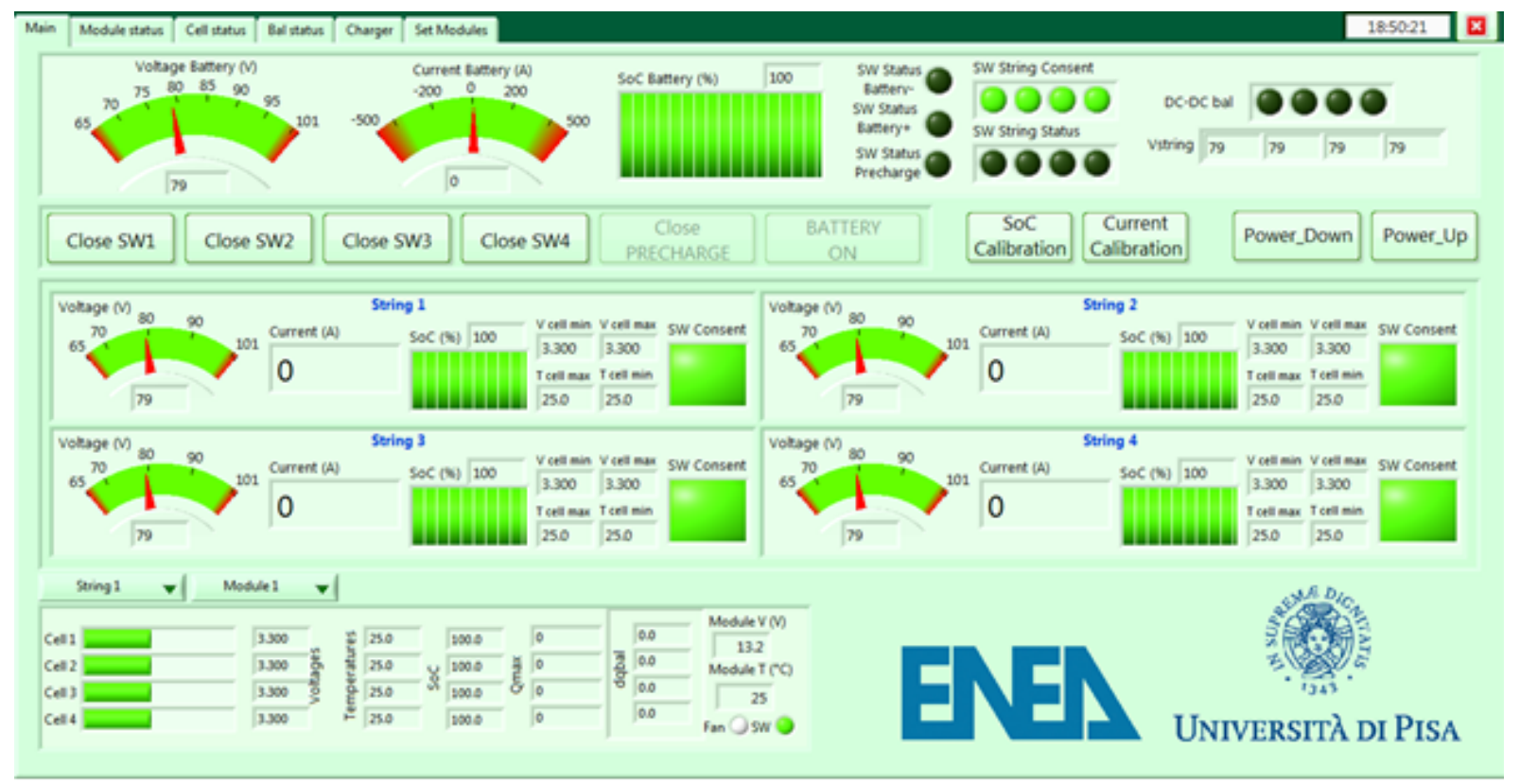

Fig. 7. Screenshot of the Main tab of the User Interface developed in LabVIEW.

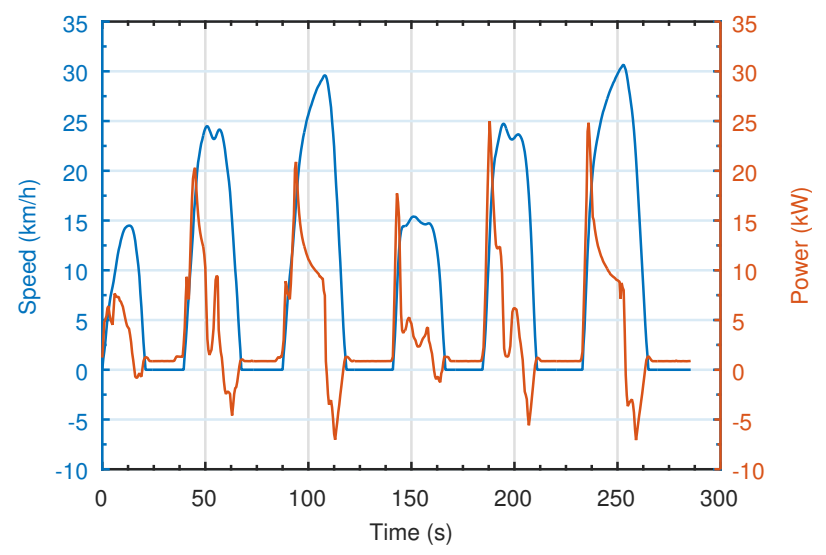

Fig. 8. Speed and electric power during two SORT 1 cycles.

TABLE IV

FULL BATTERY TEST (4 STRINGS)

\begin{tabular}{lcccc}
\hline Time & \multicolumn{4}{c}{$3.5 \mathrm{~h}$} \\
Length & \multicolumn{4}{c}{$31.7 \mathrm{~km}$} \\
Number of SORT1 cycles & \multicolumn{4}{c}{86} \\
Start / End voltage & string 1 & string 2 & string 3 & string 4 \\
\hline & 35 & 40 & 41 & 44 \\
\hline Charge delivered by (A h ) & 2.64 & 3.07 & 3.09 & 3.34 \\
\hline
\end{tabular}

between the cells within a module and the external terminals, leading to a wide dispersion of the module series resistances.

2) Half battery case: Another interesting test is the evaluation of the minibus driving range when powered by only two strings. This configuration uses a battery with halved capacity yielding a significant reduction of costs. Table $\mathrm{V}$ shows the relevant results. The minibus powered by two strings runs
TABLE V

HALF BATTERY TEST (2 STRINGS)

\begin{tabular}{lcc}
\hline Time & \multicolumn{2}{c}{$2.5 \mathrm{~h}$} \\
Length & $22.5 \mathrm{~km}$ \\
Number of SORT 1 cycles & \multicolumn{2}{c}{61} \\
Start / End voltage & \multicolumn{2}{c}{$81 \mathrm{~V} / 69 \mathrm{~V}$} \\
\hline & string 3 & string 4 \\
\hline Charge delivered by $(\mathrm{A} \mathrm{h})$ & 53.8 & 53.7 \\
Energy delivered by $(\mathrm{kW} \mathrm{h})$ & 3.92 & 4.08 \\
\hline
\end{tabular}

about $22.5 \mathrm{~km}$ in $2.5 \mathrm{~h}$, using approximately $8 \mathrm{~kW} \mathrm{~h}$.

A driving range of $22.5 \mathrm{~km}$ is not sufficient for an urban minibus. However, it may be increasd by intermediate fast recharges in a very effective way. The required daily operation is achieved provided that the energy consumed during the travelling time is balanced by the recharged energy during standstill time [16]. To guarantee the balance, the ratio $r$ of the charging time $\left(T_{\text {chg }}\right)$ to the travelling time ( $\left.T_{\text {run }}\right)$ must fulfil the following equation

$$
r=\frac{T_{\text {chg }}}{T_{\text {run }}}=\frac{C v}{P_{\text {chg }}}
$$

where $C$ is the average energy consumption per kilometer, $P_{\text {chg }}$ the available charging power and $v$ the average speed. Thus, it is crucial to assess the maximum charging power that the battery can withstand.

To this end, the charging procedure shown in Fig. 9 was applied to a fully discharged battery consisting of 2 strings. In more detail, the PMU first configures the charger to deliver a current of $330 \mathrm{~A}$, which corresponds to a $2.75 \mathrm{C}$-rate. This current value remains constant until one cell reaches the upper cut-off voltage. At this point, the charger is set to constantvoltage with a value slightly lower than the battery voltage at 

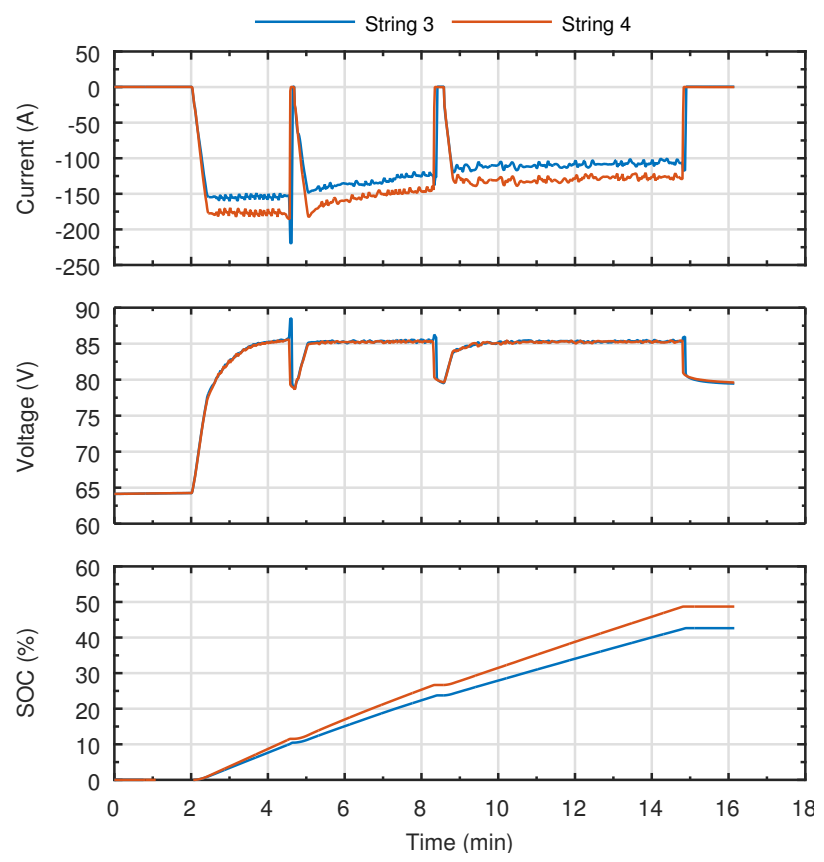

Fig. 9. Fast charging of the half battery (2 strings).

the end of the previous phase. This procedure is repeated until the battery is fully charged or the charging time is elapsed. The charging time in Fig. 9 is approximately $13 \mathrm{~min}$ and the total recharged energy is about $4.2 \mathrm{kWh}$, yielding an average charging power $P_{\text {chg }}=19.6 \mathrm{~kW}$.

Substituting the above calculated value of $P_{\text {chg }}$ and the energy consumption $C=355 \mathrm{Wh}$ (obtained at an average speed $v=9 \mathrm{~km} \mathrm{~h}^{-1}$, see Table V) in Eq. (1) yields $r=0.16$. This means that the charging time needs to be roughly $16 \%$ of the travelling time. In other words, the minibus can approximately run for 52 min every $1 \mathrm{~h}$ of operation, leading to a duty cycle of useful operation up to $87 \%$. Even if the minibus energy consumption may be higher in real use (because of the passenger weight and some friction effects modules on the dynamometer chassis), this is definitely a valuable result better than what predicted in [12].

\section{CONCLUSIONS}

This paper has discussed the feasibility analysis of the continuous operation of an electric minibus with a small size battery, combined with the fast charge approach. The study is based on replacing the original lead-acid battery of a commercial electric minibus with a lithium one. The new battery consists of 24 standard $12 \mathrm{~V}$ modules with $60 \mathrm{~A} \mathrm{~h}$ capacity and an advanced hierarchical BMS. The battery is organized in 4 strings, each of them composed of 6 seriesconnected modules.

The performance of the minibus has been assessed using a dynamometer chassis and a standard driving cycle. Tests showed that the minibus with the full battery (4 strings) can guarantee the expected driving range. They also highlighted that variations in the series resistance of the strings is detrimental to the usable capacity of the battery. Moreover, tests performed when the minibus is powered by just 2 strings showed that a daily operation of the minibus with a duty cycle of useful operation up to $87 \%$ can be achieved, provided that the battery is fast recharged during the minibus standstill time. This represents a significant step, based on experimental results, toward the assessment of the feasibility of continuous operation of an electric minibus with a small sized battery and the fast charge policy.

\section{REFERENCES}

[1] Roadmap to a Single European Transportation Area - Towards a competitive and resource efficient transport system, 2011.

[2] X. C. Wang and J. A. González, "Assessing Feasibility of Electric Buses in Small and Medium-Sized Communities," Int. J. Sustain. Transp., vol. 7, no. 6, pp. 431-448, Nov. 2013.

[3] M. D. Gennaro, E. Paffumi, H. Scholz, and G. Martini, "Analysis and assessment of the electrification of urban road transport based on real-life mobility data," in Electric Vehicle Symposium and Exhibition (EVS27), 2013 World, Nov 2013, pp. 1-12.

[4] A. T. de Almeida, C. Inverno, and L. Santos, "Integration of renewable energies for trolleybus and mini-bus lines in Coimbra," World Electr. Veh. J., vol. 3, no. 1, 2009.

[5] M. Conte, A. Genovese, F. Ortenzi, and F. Vellucci, "Hybrid battery-supercapacitor storage for an electric forklift: a life-cycle cost assessment," J. Appl. Electrochem., vol. 44, no. 4, pp. 523-532, Apr. 2014.

[6] N. Faria, P. G. Pereirinha, and J. P. Trovao, "Modelling of an urban electric minibus using energetic macroscopic representation graphic description," in Vehicle Power and Propulsion Conference (VPPC), 2015 IEEE, Oct 2015, pp. 1-6.

[7] G. Ren, G. Ma, and N. Cong, "Review of electrical energy storage system for vehicular applications," Renew. Sustain. Energy Rev., vol. 41, pp. 225-236, Jan. 2015.

[8] F. Vellucci, G. Pede, M. Ceraolo, and T. Huria, "Electrification of offroad vehicles : examining the feasibility for the Italian market," in EVS26 Int. Batter. Hybrid Fuel Cell Electr. Veh. Symp., 2012, pp. 1-17.

[9] F. Vellucci, G. Pede, F. D'Annibale, A. Mariani, R. Roncella, R. Saletti, F. Baronti, and G. Fantechi, "Development and realization of lithium-ion battery modules for starting applications and traction of off-road electric vehicles," in 2013 World Electr. Veh. Symp. Exhib. IEEE, Nov. 2013, pp. 1-10.

[10] F. Baronti, G. Fantechi, R. Roncella, R. Saletti, G. Pede, and F. Vellucci, "Design of the battery management system of LiFePO4 batteries for electric off-road vehicles," in 2013 IEEE Int. Symp. Ind. Electron. IEEE, May 2013, pp. 1-6.

[11] F. Baronti, R. Roncella, R. Saletti, G. Pede, and F. Vellucci, "Smart LiFePO4 battery modules in a fast charge application for local public transportation," in AEIT Annu. Conf. - From Res. to Ind. Need a More Eff. Technol. Transf. (AEIT), 2014, Sep. 2014, pp. 1-6.

[12] F. Baronti, R. Di Rienzo, R. Moras, R. Roncella, R. Saletti, G. Pede, and F. Vellucci, "Implementation of the fast charging concept for electric local public transport: The case-study of a minibus," in 2015 IEEE 13th Int. Conf. Ind. Informatics. IEEE, Jul. 2015, pp. $1284-1289$.

[13] Y.-M. Jeong, Y.-K. Cho, J.-H. Ahn, S.-H. Ryu, and B.-K. Lee, "Enhanced Coulomb counting method with adaptive SOC reset time for estimating OCV," in 2014 IEEE Energy Convers. Congr. Expo. IEEE, Sep. 2014, pp. 1313-1318.

[14] F. Baronti, C. Bernardeschi, L. Cassano, A. Domenici, R. Roncella, and R. Saletti, "Design and Safety Verification of a Distributed Charge Equalizer for Modular Li-Ion Batteries," IEEE Trans. Ind. Informatics, vol. 10, no. 2, pp. 1003-1011, May 2014.

[15] F. Baronti, R. Di Rienzo, N. Papazafiropulos, R. Roncella, and R. Saletti, "Investigation of series-parallel connections of multi-module batteries for electrified vehicles," in 2014 IEEE Int. Electr. Veh. Conf., 2014, pp. $1-7$.

[16] P. Sinhuber, W. Rohlfs, and D. U. Sauer, "Conceptional considerations for electrification of public city buses - Energy storage system and charging stations," in 2010 Emobility - Electr. Power Train. IEEE, Nov. 2010, pp. 1-5. 